\title{
A new Manganese superoxide dismutase mimetic improves oxaliplatin induced neuropathy and global tolerance on mice.
}

Caroline Prieux-Klotz ( $\nabla$ prieuxcaroline@gmail.com )

HIA Percy: Hopital d'Instruction des Armees Percy https://orcid.org/0000-0001-8749-651X

Hélène Bertrand

Ecole nationale superieure de chimie de Paris

Sandrine Chouzenoux

Institut Cochin

Charlotte Chêne

Institut Cochin

Marine Thomas

Institut Cochin

Clotilde Policar

Ecole Nationale Superieure de Chimie de Paris: Ecole nationale superieure de chimie de Paris

Frederic Batteux

Institut Cochin

Carole Nicco

Institut Cochin

Romain Coriat

Hôpital Cochin: Hopital Cochin

\section{Research Article}

Keywords: Superoxide dismutase mimetic, colorectal cancer, oxaliplatin induced peripheral neuropathy

Posted Date: January 31st, 2022

DOI: https://doi.org/10.21203/rs.3.rs-1287272/v1

License: (c) (i) This work is licensed under a Creative Commons Attribution 4.0 International License.

Read Full License 
A new Manganese superoxide dismutase mimetic improves oxaliplatin induced neuropathy and global tolerance on mice.

Caroline Prieux-Klotz (1,2), Hélène Bertrand (3), Sandrine Chouzenoux (1), Charlotte Chêne (1), Marine Thomas (1), Clotilde Policar (3), Frédéric Batteux (1), Carole Nicco* (1) and Romain Coriat* $(1,4)$.

(1) Institut Cochin, INSERM U 1016 CNRS UMR 8104, Université de Paris, France

(2) Gastroenterology Percy Military Hospital, Clamart France

(3) Laboratoire des biomolécules, LBM, Département de chimie, Ecole normale supérieure, PSL University, Sorbonne Université, CNRS, 75005 Paris, France

(4) Gastroenterology, Cochin Hospital AP-HP, Université de Paris, France

*The two co-last authors have contributed equally to this work

Corresponding author: Caroline Prieux-Klotz, Percy military hospital, Gastroenterology, 101 avenue Henri Barbusse 92140 Clamart France. prieuxcaroline@ gmail.com Tel:

$+33672078783$

Key words: Superoxide dismutase mimetic, colorectal cancer, oxaliplatin induced peripheral neuropathy.

Abbreviations:

ROS : Reactive Oxygen Species

DNA : Deoxyribonucleic Acid

NADPH : Nicotinamide Adenine Dinucleotide Phosphate

MnSOD : Manganese Superoxide Dismutase

$\mathrm{H}_{2} \mathrm{O}_{2}$ : Hydrogen peroxide

$02^{-}$: superoxide anion

GSH : Glutathione

CT26 : Mus musculus colon carcinoma cell line

HCT116 : human colon cancer cell line

$\mathrm{KC}$ : mouse pancreatic ductal carcinoma cell line

NIH 3T3: mouse embryonic fibroblast cell line

ENS: Ecole Normale Supérieure

$\mu \mathrm{M}$ : micromolar

M: molar

Words count: Abstract: $460 \quad$ Manuscript: 4723

Ref: 43

Tables: $\quad 0 \quad$ Figures: 10 Supplementary 2 
Abstract

Introduction: Reactive oxygen species (ROS) are produced by every aerobic cell during mitochondrial oxidative metabolism as well as in cellular response to xenobiotics, cytokines, and bacterial invasion. Oxidative stress is due to an imbalance between ROS or oxidants generation over the capability of the cell to elaborate an effective antioxidant response. Superoxide Dismutases (SOD) are antioxidant proteins that convert superoxide anion $\left(\mathrm{O}_{2}{ }^{\circ-}\right)$ to hydrogen peroxide $\left(\mathrm{H}_{2} \mathrm{O}_{2}\right)$. SOD mimetics can enhance the production of $\mathrm{H}_{2} \mathrm{O}_{2}$ and improve cytotoxic effect of chemotherapy. By using the differential in level of oxidative stress between normal and cancer cells, SOD mimetics can show an anti-tumoral effect and prevent oxaliplatin induced neuropathy. A new Pt(IV) conjugate prodrug called MAGOX, combining oxaliplatin and a Mn SOD mimic (MnSODm Mn1C1A) with a covalent link, was created. Methods: In vitro, MAGOX anti-tumoral activity was assessed by the viability and ROS production of tumor cell lines (CT16, HCT 116, KC) and fibroblasts (primary culture and NIH 3T3) treated with Mn1C1A alone, conjugates (MAG2OX, MAGOX mono-OH, MAGOX mono-OAc), oxaliplatin and vehicle. In vivo, a murine model of colorectal cancer was created with subcutaneous injection of CT26 cells. After tumor growth, Balb/c mice underwent randomization in 4 groups: vehicle, oxaliplatin, MAG2OX and Mn1C1A. Tumor size and volume were measured weekly. Oxaliplatin induced peripheral neuropathy was assessed using a Von Frey test reflecting chronic hypoalgesia. Tolerance to treatment was assessed with a clinical score including 4 items: weight loss, weariness, alopecia and diarrhea. Results: In vitro, the MnSODm associated with oxaliplatin and MAG2OX treatment induced a significant higher production of $\mathrm{H}_{2} \mathrm{O}_{2}$ in all cell lines, by itself. In the group of cell lines treated with the association of $\mathrm{Mn} 1 \mathrm{C} 1 \mathrm{~A}$ and oxaliplatin and the group treated with MAG2OX, a significant improvement of the anti-tumoral efficacy compared to oxaliplatin alone was observed. In vivo, the association of Mn1C1A to oxaliplatin did not decrease its 
anti-tumoral activity and MAG2OX had a lower anti-tumoral activity than oxaliplatin alone. Mn1C1A associated with oxaliplatin significantly decreased oxaliplatin induced peripheral neuropathy and also improved global clinical tolerance of oxaliplatin, therefore mice treated with Mn1C1A + oxaliplatin could receive more cumulated dose of oxaliplatin. Seric advanced oxidative protein products were higher in the Mn1C1A + oxaliplatin group versus oxaliplatin alone. PCR VEGF showed a higher VEGF RNA production in tumoral cells of mice treated with Mn1C1A than the other groups, as well as higher production of LC3 reflecting autophagy. Conclusion: A new Mn SOD mimetic called Mn1C1A associated with oxaliplatin showed superior anti tumoral activity than oxaliplatin, in vitro. The first $\mathrm{Pt}(\mathrm{IV})$ conjugate MAGOX had lower antitumoral activity, probably due to chemical instability issues. A new design is being evaluated. In vivo we observed a neuroprotective effect associated with a tolerance to oxaliplatin significantly improved, without impairing its antitumoral activity. 
Introduction

Reactive oxygen species (ROS) are highly reactive oxygenated chemical species. All eukaryotic cells, due to their aerobic cellular metabolism, are producing ROS. Superoxide anion $\left(\mathrm{O}_{2}{ }^{--}\right)$is a free radical, toxic for the cell, which is transformed in hydrogen peroxide $\left(\mathrm{H}_{2} \mathrm{O}_{2}\right)$ by an enzyme called superoxide dismutase. The Manganese superoxide dismutase (Mn-SOD) is located in the mitochondria, and indispensable for life (1). An increased oxidative stress is due to a disbalance between ROS production and detoxification. Cellular homeostasis is maintained by the presence of detoxification systems such as SODs, catalase, glutathione (GSH)) (2). At low intracellular concentrations ROS production can lead to cellular proliferation and protection (3)(4)(5), higher levels produce an antitumoral activity (6) (7).

Cancer cells were found to have increased sensitivity to oxidative stress compared to normal cells (8), due to a lower detoxification system and higher basal ROS production, close to the toxic threshold (9).

Superoxide dismutase mimetics have been developed to experiment their antitumoral activity. SOD mimetic led to an increase of cellular $\mathrm{H}_{2} \mathrm{O}_{2}$ and increased the antitumoral activity of chemotherapy in vitro, due to the difference of hydrogen peroxide cellular sensitivity between normal and cancer cells (6)(10)(11)(3)(12). In particular, Mangafodipir, a contrast agent used in magnetic resonance imaging that concentrates in the liver and displays superoxide dismutase antioxidant properties, has been shown to prevent colorectal tumor growth in mice (13). It has been shown that mangafodipir can prevent and/or relieve oxaliplatin-induced neuropathy in cancer patients (21). Oxaliplatin is a major drug in digestive oncology, in adjuvant (14) or metastatic situation $(15)(16)(17)(18)(19)$, in colorectal cancer but also in oesogastric cancer, pancreatic adenocarcinoma and bile duct carcinoma. Platinum derivatives 
are among the most common anticancer agents more prescribed, they are indeed used to treat a broad spectrum of human tumors. They are intercalating agents that form adducts to the DNA of cells. Thus, oxaliplatin induces cell cycle blockade and cell apoptosis. This chemotherapy leads to an oxidative burst in the cancer cell, which is part of its antitumoral activity (6). Oxaliplatin induced peripheral neuropathy occurs in $>90 \%$, responsible of chronic pain and disability, and is dose-limiting(20). It has been shown that oxaliplatin induced peripheral neuropathy was induced by the oxidative burst and the direct toxicity of $\mathrm{O}_{2}$ - in the dorsal ganglion (21). Mangafodipir, as a Mn-SOD mimetic, has been shown as neuroprotective when co administrated with oxaliplatin, leading to a significant decrease of oxaliplatin induced peripheral neuropathy, in mice and in a phase I trial (22). In Coriat and al work, 22 cancer patients with grade $\geq 2$ oxaliplatin-associated peripheral neuropathy received intravenous Mangafodipir following oxaliplatin. In $77 \%$ of cases, oxaliplatin-induced neurotoxicity improved or stabilized after four cycles. After eight cycles, oxaliplatin-induced neurotoxicity was downgraded in six of seven patients. Glimelius and al. (23) conducted a phase II study with 179 colorectal cancer patients with oxaliplatin induced peripheral neuropathy, randomized between calmangafodipir and placebo. Calmangafodipir-treated patients had significantly less cold allodynia (mean 1.6 versus $2.3, \mathrm{p}<.05$ ) and significantly fewer sensory symptoms in the Leonard scale (cycle $1-8$ mean 1.9 versus $3.0, \mathrm{p}<.05$ and during follow-up after 3 and 6 months, mean 3.5 versus 7.3, p <.01). Response rate, progression-free and overall survival did not differ among groups. A phase III study (POLAR study) comparing PledOx (calmangafodipir) to placebo in patients with oxaliplatin induced peripheral neuropathy was shut down early because PledOx $5 \mu \mathrm{mol} / \mathrm{kg}$ in combination with chemotherapy did not reduce the risk of moderate to severe chemo-induced peripheral neuropathy (CIPN) at 9 months after the first cycle. But mangafodipir commercialization 
stopped, replaced by gadolinium as a contrast MRI agent. Thus, mangafodipir availability has been impaired.

Moreover, the high molecular weight of mangafodipir impairing its cellular penetration has been suspected for the lack of antitumoral efficacy in vivo (9). Thus, new low molecular weight SOD mimetics were created to overcome this issue $(24)(25)(26)$. Among them, the MAG complex, bio inspired by the active site of Mn-SOD has been shown to have a better intracellular diffusion compared to mangafodipir (27)(28). Guillaumot and al. studied this complex in vitro and in vivo. In vitro, MAG induced hydrogen peroxide production in tumoral cells (HT 29, CT 26) and in embryonic fibroblasts (NIH 3T3). A cytotoxic additive effect in association with oxaliplatin was observed on cancer cells. In vivo, in a murine model of colorectal cancer, MAG in association with oxaliplatin did not have a better anti-tumoral effect than oxaliplatin but showed a significant decrease in peripheral neuropathy induced by oxaliplatin (29). A new panel of chimeric molecules in the form of $\mathrm{Pt}(\mathrm{IV})$ prodrugs that covalently link oxaliplatin with a Mn-SOD mimetic Mn1C1A, was created and called here the MAGOX compounds (composed by oxaliplatin and Mn1C1A MnSOD mimic)(30). Pt(IV) prodrugs constitute one of the alternative strategies to combination treatments devised to achieve a targeted delivery, reduced side effects and toxicity, increased anticancer activity or improved bioavailability (31). Three noticeable Pt(IV) compounds have been investigated in clinical trials(32). A covalent conjugation between the two active components is expected to present several advantages compared to a combination treatment such as allowing the control of the ratio of active components penetrating the cells; as prodrugs, the compounds will only be active once internalized and reduced in cells or tumor microenvironment. Three different MAGOX were studied: MAGOX mono-OH, MAGOX mono-OAC, and MAG2OX with 2 Mn SODm for 1 oxaliplatin. We assessed the cytotoxic activity of these new compounds in vitro (Mn1C1A and MAGOX), and their protective effect against oxaliplatin induced 
peripheral neuropathy, and their anti-tumoral activity in vivo on a murine model of colorectal cancer. 


\section{Results}

MAGOX conjugates compounds and Mn1C1A MnSODm associated with oxaliplatin increased $\mathrm{H}_{2} \mathrm{O}_{2}$ production in all cell lines.

$\underline{\text { Mean }} \mathrm{H}_{2} \mathrm{O}_{2}$ production was measured in HCT 116, CT26, NIH 3 T3 and KC cells after treatment with the 3 MAGOX compounds, oxaliplatin alone, Mn1C1A +oxaliplatin or vehicle (Figure 2).

In HCT 116 cells, treatment with Mn1C1A + oxaliplatin significantly increased mean $\mathrm{H}_{2} \mathrm{O}_{2}$ production $(\mathrm{p}<0.01)$ compared to oxaliplatin alone with all tested concentrations.

In CT26 cells, treatment with MAG2OX and Mn1C1A + oxaliplatin significantly increased mean $\mathrm{H}_{2} \mathrm{O}_{2}$ production $(\mathrm{p}<0.05)$ compared to oxaliplatin alone with all tested concentrations. In NIH 3 T3 cells, treatment with MAGOX mono OH, MAGOX mono OAc, MAG2OX and Mn1C1A+oxaliplatin significantly increased mean $\mathrm{H}_{2} \mathrm{O}_{2}$ production $(\mathrm{p}<0.001)$ compared to oxaliplatin alone with all tested concentrations.

In $\mathrm{KC}$ cells; treatment with $\mathrm{Mn} 1 \mathrm{C} 1 \mathrm{~A}+$ oxaliplatin significantly increased mean $\mathrm{H}_{2} \mathrm{O}_{2}$ production $(\mathrm{p}<0.01)$ compared to oxaliplatin alone with all tested concentrations.

In vitro anti tumoral activity was significantly higher in tumoral cell lines treated with MAGOX conjugates compounds and Mn1C1A associated with oxaliplatin compared to oxaliplatin alone. The anti-tumoral effect was proportional to $\mathrm{H}_{2} \mathrm{O}_{2}$ production.

\section{Cell viability was assessed by cristal violet at day 2 after 24 hours of treatment (3}

\section{MAGOX compounds, oxaliplatin alone, Mn1C1A+oxaliplatin or vehicle) (Figure 3).}

In HCT 116 cells, MAG2OX and Mn1C1A + oxaliplatin induced significantly more tumoral cell death than oxaliplatin ( $\mathrm{p}<0.01$ and $\mathrm{p}<0.001$ respectively).

In CT26 cells; MAG2OX and Mn1C1A + oxaliplatin induced significantly more tumoral cell death than oxaliplatin $(\mathrm{p}<0.001)$. 
In NIH3T3 cells; all conjugates MAGOX compounds and oxaliplatin+Mn1C1A induced significantly more cell death than oxaliplatin $(\mathrm{p}<0.001)$.

In KC cells, MAG2OX and Mn1C1A + oxaliplatin induced significantly more tumoral cell death than oxaliplatin $(\mathrm{p}<0.05$ and $\mathrm{p}<0.01$ respectively).

O2-- production was significantly higher in HCT 116 and NIH 3 T3 cell lines treated with Mn1C1A+oxaliplatin than oxaliplatin alone. GSH production reflecting the detoxification system was stable in CT26, HCT 116, NIH 3 T3 and lowered in KC cells treated with MnSOD mimetics.

Mean $\mathrm{O}_{2} \cdot-$ production in all cell lines was measured after 24 hours of treatment exposure.

\section{(Figure Supplementary S1).}

In $\mathrm{HCT} 116$ cells, oxaliplatin+Mn1C1A increased significantly $\mathrm{O}_{2}^{--}$production compared to oxaliplatin alone $(\mathrm{p}<0.05)$.

In CT26 and $\mathrm{KC}$ cells, no significant difference was observed in $\mathrm{O}_{2}$ - production.

In NIH $3 \mathrm{~T} 3$ cells, MAG2OX and oxaliplatin+Mn1C1A increased significantly $\mathrm{O}_{2} \cdot-$ production compared to oxaliplatin alone $(\mathrm{p}<0.05)$.

The mean GSH production reflecting detoxification system was the same in each treatment group for HCT 116, CT26 and NIH 3 T3 (igure Supplementary S2)

In KC cells; GSH production was significantly lower with the MAGOX compounds (mono $\mathrm{OH}$, mono OAc, MAG2OX) and the Mn1C1A+oxaliplatin treatment versus oxaliplatin alone $(\mathrm{p}<0.01$ and $\mathrm{p}<0.05$ respectively).

The MAGOX conjugates and oxaliplatin + Mn1C1A had significantly higher cytotoxicity on primary fibroblast culture cells than oxaliplatin alone. The MnSODm Mn1C1A alone was not cytotoxic on fibroblasts. 
Cell viability assessed by cristal violet was measured on a primary culture of murine fibroblasts (Figure 4).

Oxaliplatin+ Mn1C1A, MAGOX mono OH, MAGOX mono OAc and MAG2OX had significantly more cytotoxicity than oxaliplatin alone and vehicle $(\mathrm{p}<0.05)$. Treatment with Mn1C1A alone was not more cytotoxic than vehicle or oxaliplatin on fibroblasts.

In vivo, tumoral growth was faster in the MAG2OX group than in mice treated with oxaliplatin alone. Thus, mice treated with Mn1C1A+oxaliplatin had the same tumoral growth evolution than mice treated with oxaliplatin alone.

The tumoral volume was followed during treatment of Balb/c mice inoculated with CT26 tumoral cells, treated with vehicle, oxaliplatin, MAG2OX or Mn1C1A+oxaliplatin (Figure

\section{5).}

In the control group treated with vehicle, tumoral growth was exponential. Mice treated with MAG2OX had a significantly lower tumoral growth than the control group but a significantly faster tumoral growth than mice treated with oxaliplatin alone $(\mathrm{p}<0.05)$.

The association of Mn1C1A to oxaliplatin did not affect its antitumoral activity. Mice treated with Mn1C1A+oxaliplatin had the same and highest tumoral response, compared to MAG2OX and control.

Mice treated with oxaliplatin alone had a significantly poorer clinical tolerance than mice treated with Mn1C1A + oxaliplatin. Thus, $80 \%$ of mice treated with oxaliplatin could not receive their second injection due to a severe weight loss but every injection could be received in the Mn1C1A+ oxaliplatin group with no significant weight loss. The clinical tolerance of treatment was assessed with clinical score composed with 4 items (weight loss (0-2), alopecia (0-2), diarrhea (0-1) and asthenia (0-2)) measured in all mice treated with vehicle, oxaliplatin $10 \mathrm{mg} / \mathrm{kg}$ weekly (IP), Mn1C1A+oxaliplatin $10 \mathrm{mg} / \mathrm{kg}$ weekly 
(IP), and MAG20X 10mg/kg weekly (IP) (Figure 6) The higher the score was, the poorer the clinical tolerance was.

Figure 6A shows the mean clinical score during the whole experimentation. Mice treated with Mn1C1A+ oxaliplatin had a significantly lower clinical score showing a better clinical tolerance of the treatment $(\mathrm{p}<0.01)$ than mice receiving oxaliplatin alone with the same dose. Mice treated with the conjugate MAG2OX had also a significantly lower clinical score than mice treated with oxaliplatin alone $(\mathrm{p}<0.05)$.

Figure 6B shows the clinical score evolution over time. Mice treated with oxaliplatin alone had a mean high clinical score (4) after 1 intraperitoneal injection and $80 \%$ could not receive the second injection due to a weight loss>20\%. In the vehicle, MAG2OX and Mn1C1A+oxaliplatin group, each mouse received weekly injections.

\section{Mice treated with oxaliplatin + Mn1C1A showed significant less hypoalgesia induced by oxaliplatin than mice treated with oxaliplatin alone.}

Von Frey test reflecting chronic hypoalgesia, with the force (grams) necessary to induce a paw withdrawal was performed before treatment and during the whole experiment (Figure 7). Figure 7A shows mean Von Frey score during the whole experiment in mice treated with vehicle, oxaliplatin, Mn1C1A+oxaliplatin and MAG2OX. In the Mn1C1A+oxaliplatin group, significantly less hypoalgesia occurred than in the oxaliplatin alone group (mean: $2,57 \mathrm{~g}$ vs 3,95g, $\mathrm{p}<0.05)$. The difference between MAG2OX and oxaliplatin alone was not significant. Figure 7B shows the Von Frey score evolution over time (days). Mice treated with oxaliplatin had a progressive chronic hypoalgesia with a raise of the force necessary to withdraw their paw. Mice treated with the same dose of oxaliplatin associated with Mn1C1A had the same behaviour than mice treated with vehicle. 
Seric advanced oxidation protein products (AOPP) reflecting oxidative stress in mice treated with Mn1C1A + oxaliplatin and MAG2OX were significantly lower than in mice treated with oxaliplatin alone.

The mean AOPP level in mice serum was measured after sacrifice (Figure 8). Oxidative stress represented by seric AOPP was significantly lower in the Mn1C1A+oxaliplatin and MAG2OX group than in the oxaliplatin group ( $<<0.001$ and $<0.05$ respectively), reflecting the Mn-SOD activity of our molecules.

Tumoral tissue analysis of mice treated with either vehicle, oxaliplatin, MAG2OX or Mn1C1A+oxaliplatin showed significant higher VEGF RNA production in mice treated with Mn1C1A+oxaliplatin and higher LC3 production in Western blot. After sacrifice, tumoral RNA of VEGF was measured with PCR (Figure 9). Figure 9A represents PCR VEGF / $\beta$ actin in tumoral tissue of mice treated with either vehicle, oxaliplatin, MAG2OX or Mn1C1A+oxaliplatin, showing a significant higher production of VEGF RNA in the Mn1C1A+oxaliplatin group.

Figure 9B represents the autophagy marker LC3 measured in western blot, showing a significant higher production of the LC3 protein in the Mn1C1A+oxaliplatin group. There was no difference of SQSTM1 production among the groups.

\section{Histological analysis}

No significant difference of histological tumoral analysis has been found between the groups.

Caspase 3 expression in immunohistochemistry was dependent of tumoral response.

Luxol fast blue coloration in paw skin showed no significant difference between the groups. 



\section{$\underline{\text { Discussion }}$}

In vitro the new conjugate compounds MAGOX, Manganese superoxide dismutase mimetic associated with oxaliplatin and the Mn1C1A MnSODm associated with oxaliplatin showed significant raise of $\mathrm{H}_{2} \mathrm{O}_{2}$ production associated with superoxide dismutase activity, in tumoral and fibroblasts cell lines compared to oxaliplatin alone. This MnSOD activity, represented by the $\mathrm{H}_{2} \mathrm{O}_{2}$ production was proportional to the in vitro anti-tumoral activity, with the strongest cytotoxicity for the association Mn1C1A + oxaliplatin. This result confirms our hypothesis of an oxidative burst maximizing anti-tumoral activity of oxaliplatin and is the same effect as observed by Guillaumot and al. (29) with MAG and Coriat and al. (13). The O2.- levels were not lower in cells treated with MnSODm, as expected. This result may be explained by the delay of the measure ( 24 hours after treatment), that is potentially late for an O2.- change in cellular production (33).

Although the Mn1C1A alone was not cytotoxic on primary fibroblasts, the conjugate compounds showed higher toxicity in fibroblasts and NIH3T3 cells than oxaliplatin alone. This result is surprising due to the fact that tumoral cells show a lower cytotoxic threshold of $\mathrm{H}_{2} \mathrm{O}_{2}$ than normal cells. This result can be explained by the high raise of $\mathrm{H}_{2} \mathrm{O}_{2}$ production, with MAGOX, exceeding all thresholds. This result contrasts with the good in vivo tolerance of the conjugate compounds (clinical, haematological).

In vivo, in our model of murine colorectal cancer with subcutaneous injection of CT26 cells, the association of Mn1C1A to oxaliplatin did not reduce its antitumoral activity but did not maximize its antitumoral activity. The same phenomenon was observed by Guillaumot and al. (29) with the MAG. Also the intra tumoral penetration of the compound is not certain, but the presence of AOPP in the mice sera reflects a seric Mn SOD activity in vivo. For the MAG2OX conjugate compound, a lower antitumoral activity than oxaliplatin alone was observed, and no significant neuroprotective effect. In the different conditions, the lower anti tumoral activity of 
MAG2OX could be explained by the lower relative dose of Platinum received : In oxaliplatin, $10 \mathrm{mg} \cdot \mathrm{kg}^{-1}=4.91 \mathrm{mg} \cdot \mathrm{kg}^{-1}$ of Pt, in oxaliplatin and Mn1C1A, $10 \mathrm{mg} \cdot \mathrm{kg}^{-1}$ of each compound = $4.91 \mathrm{mg} \cdot \mathrm{kg}^{-1}$ of Pt and $1.095 \mathrm{mg} \cdot \mathrm{kg}^{-1}$ of $\mathrm{Mn}$, but in MAG2OX, $10 \mathrm{mg} \cdot \mathrm{kg}^{-1}=1.39 \mathrm{mg} \cdot \mathrm{kg}^{-1} \mathrm{of} \mathrm{Pt}$ and $0.785 \mathrm{mg} \cdot \mathrm{kg}^{-1}$ of $\mathrm{Mn}$. Furthermore, intratumoral and intracellular concentrations of MAG2OX will be measured as well as Mn1C1A concentration.

Detailed physicochemical studies on the MAGOX series using UV-Vis titrations and HPLC demonstrated an unexpected instability of these conjugates upon Mn coordination of the ligand and fast degradation ( $\mathrm{t}_{1 / 2}$ between $30 \mathrm{~min}$ for MAGOX-MonoOAc and $2 \mathrm{~h}$ for MAG2OX) leading us to propose a cleavage of the Pt-O bond with the folding of the carboxylate arm onto the Mn (favoured by the formation of 5-membered metallacycle) (Figure 10)(30). The in situ preparation of the MAGOX compounds for the cellular assays and in vivo injections therefore leads to a mixture of compounds that depends on the time scale of the experiment: MAGOX conjugate, Mn1C1A and a Pt species yet to determine. A new MAGOX generation demonstrating complete stability upon Mn coordination and suitable kinetics of reduction to $\mathrm{Pt}(\mathrm{II})$ was designed and their activity will be reported in due course. Another explanation of the lack of additive antitumoral effect in vivo is the vascular protective effect of Mn SOD mimetics, with increase of VEGF production which has already been showed with these molecules (34)(35). We showed a significant raise of VEGF production with the MnSODm Mn1C1A associated with oxaliplatin group with the highest AOPP production sign of a higher oxidative burst. VEGF production by tumoral cells participates to tumor growth and proliferation (36). With increasing VEGF production and thus neoangiogenesis stimulation could impair the additional antitumoral activity of our molecule. An association between the Mn1C1A or the conjugate MAGOX and an anti VEGF as already used in colorectal cancer such as bevacizumab or aflibercept could be interesting in further studies.

The role of autophagy in tumoral response is crucial in colorectal cancer. It has been shown in human colorectal tumors that surexpression of Beclin-1 was a poor prognosis factor with a lower efficacity of chemotherapy (37). Oxaliplatin inhibits autophagy in colorectal cancer with 
microsatellite stability (38). The oxidative burst on the contrary induces autophagy as shown in the literature and in our experiment with a higher LC3 tumoral production in the Mn1C1A+oxaliplatin group. An association of the MnSODm with an autophagy inhibitor could be interesting to maximise anti tumoral activity of the MnSODm.

In vivo, the association of $\mathrm{Mn} 1 \mathrm{C} 1 \mathrm{~A}$ to oxaliplatin significantly reduced oxaliplatin induced peripheral neuropathy compared to the oxaliplatin group. This neuroprotective effect has been shown in mice and humans with MnSOD mimetics (22)(29) with a protection from demyelinisation. The significant efficacy with the Mn1C1A MnSODm in mice, should therefore be confirmed on phase I trials associated to oxaliplatin.

The association of Mn1C1A and oxaliplatin is the first one to have shown a better global tolerance of oxaliplatin with a clinical score based on weight loss, fatigue, diarrhea and alopecia. Mice receiving Mn1C1A with the same full dose of oxaliplatin than mice receiving oxaliplatin alone had a significant better clinical tolerance of the treatment and therefore received more oxaliplatin at the end of the experiment, compared to mice receiving oxaliplatin alone whom $80 \%$ did not receive the second injection due to their significant weight loss. The improvement of clinical tolerance without impairing antitumoral efficacy associated with a neuroprotective effect raises the oxaliplatin cumulative dose tolerated and therefore could improve its antitumoral efficacy. In the study by Guillaumot et al. (29), MAG showed a significant in vitro tumoral cytotoxicity, a neuroprotective effect in vivo but no anti tumoral activity in vivo. Clinical tolerance was not assessed.

In conclusion, this new Mn SOD mimetic Mn1C1A, when associated to oxaliplatin, improves clinical tolerance in vivo of oxaliplatin and prevents oxaliplatin induced peripheral neuropathy, without impairing its antitumoral activity. Given these results, this new Mn SOD mimetic molecule shows promising perspectives with clinical relevance and should be confirmed in 
human phase I clinical trial. Our Pt(IV) prodrug strategy combining oxaliplatin and a MnSODm in a covalent conjugate will be evaluated with the optimized MAGOX series. 
Material and Methods

\section{Ligand and conjugate compounds creation}

The MnSOD active compound called Mn1C1A was synthetized in a chemistry laboratory (ENS Paris, Pr Policar, Dr Bertrand), with a chemical formula $\mathrm{C}_{21} \mathrm{H}_{26} \mathrm{MnN}_{6} \mathrm{O}_{3}$ and a molecular weight of 465.14. Three Pt(IV) complexes of derived from oxaliplatin with a MnSODm were designed and synthesized: the MAGOX Mono OH complex, formulated $\mathrm{C}_{29} \mathrm{H}_{41} \mathrm{ClMnN}_{8} \mathrm{O} 8 \mathrm{Pt}$, with a molecular weight of 914.18 (associated ligand $\mathrm{C}_{2} \mathrm{H}_{42} \mathrm{~N}_{8} \mathrm{O}_{8} \mathrm{Pt}$ $825.78 \mathrm{~g} / \mathrm{mol}$ ), the MAGOX mono-OAc complex formulated $\mathrm{C}_{31} \mathrm{H}_{43} \mathrm{ClMnN}_{8} \mathrm{O} 9 \mathrm{Pt}$, with a molecular weight of 957.20 (associated ligand $\mathrm{C}_{31} \mathrm{H}_{44} \mathrm{~N}_{8} \mathrm{O} 9 \mathrm{Pt}$, molecular weight 867.81 $\mathrm{g} / \mathrm{mol}$ ) and the MAG2OX complex formulated $\mathrm{C}_{50} \mathrm{H}_{66} \mathrm{Cl}_{2} \mathrm{Mn}_{2} \mathrm{~N}_{14} \mathrm{O}_{10} \mathrm{Pt}$, with a molecular weight of $1397.29 \mathrm{~g} / \mathrm{mol}$ (associated ligand $\mathrm{C}_{50} \mathrm{H}_{68} \mathrm{~N}_{14} \mathrm{O}_{10} \mathrm{Pt}$ with a weight of $1220.25 \mathrm{~g} / \mathrm{mol}$ ). These compounds and Mn1C1A were prepared in situ by mixing the corresponding titrated ligands in aqueous solutions (molecules non coordinated to $\mathrm{Mn}$ ) with a solution of $\mathrm{MnCl}_{2}$ $\left(\mathrm{M}=125.84 \mathrm{~g} \cdot \mathrm{mol}^{-1}\right)$ in HEPES $(100 \mathrm{mM}, \mathrm{pH} 7)$ at a $4 \mathrm{mM}$ concentration at the desired ratio: 1:1 molar ratio (ligand:Mn) for Mn1C1A, MAGOX mono-OH and MAGOX mono-OAc and 1:2 molar ratio for MAG2OX.

\section{Cell cultures and treatments}

All immortalized cell lines were routinely tested for mycoplasma. All cell lines were purchased from the ATCC. Mouse embryonic fibroblast cells (NIH 3T3), mouse colorectal cancer cells (CT26), mouse pancreatic cancer cells (KC) and human colorectal cancer cells (HCT 116) were grown in Dulbecco's Modified Eagle Medium high glucose 500mL (Thermofisher ${ }^{\circledR}$, Waltham, Massachussets, USA) with 10\% Fetal bovine serum 
(Thermofisher ${ }^{\circledR}$ ) and $5 \mathrm{~mL}$ penicillin/streptomycin (Thermofisher ${ }^{\circledR}$ ). Primary fibroblast cell culture was isolated from mouse skin and grown in the same culture medium.

\section{ROS production in vitro}

When grown to confluence, the different cell lines were treated with trypsin (Thermofisher $\left.{ }^{\circledR}\right)$, counted, and seeded in flat bottom 96-well plates (Corning® New York, USA). CT 26, KC, HCT 116 cells were seeded with $10^{5}$ cells/well, and NIH 3T3 with $5.10^{4}$ cells/well. A decreasing range was made for each cell line. After 24 hours, experimental treatment was applied in triplicates, with different concentrations: $2,5 \mu \mathrm{M}, 5 \mu \mathrm{M}, 10 \mu \mathrm{M}$ of oxaliplatin, Mn1C1A + oxaliplatin, MAGOX mono OH, MAGOX mono-OAc, MAG2OX, or control (culture medium). After 24 hours of treatment exposure, cell production of $\mathrm{H}_{2} \mathrm{O}_{2}, \mathrm{GSH}, \mathrm{O}_{2}{ }^{-}$ were assessed by spectrofluorimetry with 2-7 diChlorodihydroFluorescein Diacetate $\left(\mathrm{H}_{2}-\right.$ DCFDA), monochlorobimane and Dihydroethidium (DHE) (D23107, Thermofisher®, Waltham, USA) respectively. Cells were washed with Phosphate Buffer saline (PBS) and incubated in a dark environment with $100 \mu \mathrm{L}$ per well of $5 \mu \mathrm{M} \mathrm{H}_{2}$-DCFDA (D399, Thermofisher®, Waltham, USA), $15 \mu \mathrm{M}$ DHE and $5 \mu \mathrm{M}$ monochlorobimane (M1381MP, Thermofisher ${ }^{\circledR}$, Waltham, USA), diluted in PBS. ROS levels were assayed by spectrofluorimetry on a Fusion spectrofluorimeter (Packard Bell $®)$ and fluorescence intensity was recorde every hour over a period of 6 hours. A cristal violet viability was assessed at the same time for each cell line and ROS production was calculated with subtraction of fluorescence between Hour 6 and Hour H0 reported to Cristal Violet viability. Student $\mathrm{t}$ and ANOVA test were performed.

\section{Cell viability in vitro}

When grown to confluence, the different cell lines were treated with trypsin (Thermofisher $\left.{ }^{\circledR}\right)$, counted, and seeded in flat bottom 96-well plates (Corning ${ }^{\circledR}$ New York, USA). CT 26, KC, HCT 116 cells were seeded with $10^{5}$ cells/well, and NIH 3T3 with $5.10^{4}$ cells/well. A 
decreasing range was made for each cell line. After 24 hours, experimental treatment was applied in triplicates, with different concentrations: $2,5 \mu \mathrm{M}, 5 \mu \mathrm{M}, 10 \mu \mathrm{M}$ of oxaliplatin, Mn1C1A +oxaliplatin, MAGOX mono OH, MAGOX mono-OAc, MAG2OX, or control (culture medium). For primary fibroblasts, $10^{4}$ cells per well were seeded and the experimental treatment was applied after 48 hours, with $2,5 \mu \mathrm{M}, 5 \mu \mathrm{M}, 10 \mu \mathrm{M}$ of oxaliplatin, Mn1C1A+oxaliplatin, MAGOX mono OH, MAGOX mono-OAc, MAG2OX and ligand alone, or control. For all cells, the treatment was removed from the well after 24 hours and replaced by cell medium. Cell viability was assessed 24 hours later by cristal violet assay, and read with spectrofluorometry (Fusion, Packard Bell $\left.{ }^{\circledR}\right)$.

\section{Animals}

Mice model was performed on Balb/c female mice, aged 6 weeks, purchased from Janvier Labs ${ }^{\circledR}$. All animals were housed in ventilated cages, from 7 to 10 per cages, with rodent diet and water ad libitum (Teklad global 16\% protein, Envigo®). All animals were exposed to a standard light cycle of 12 hours on and 12 hours off. All efforts were pursued to minimize animal distress and to reduce the number of animals used. Mice were euthanized by cervical dislocation under isoflurane $+0_{2}$ anesthesia. All animal manipulations were presented and approved by the Ethics Comitee of Paris University (Saisine \#8394). All experiments were performed in accordance with European and French institutional guidelines).

\section{Colorectal cancer mice model}

A subcutaneous injection was performed of $1.5 .10^{6} \mathrm{CT} 26$ cells on female Balb/c mice aged 6 weeks. Until a measurable tumoral growth, mice were randomized in 4 groups with similar mean tumor size. One group of 8 mice received oxaliplatin $10 \mathrm{mg} / \mathrm{kg} /$ week by intraperitoneal injection, a group of 9 mice received MAG2OX $10 \mathrm{mg} / \mathrm{kg} /$ week by intraperitoneal injection, 9 mice received $\mathrm{Mn} 1 \mathrm{C} 1 \mathrm{~A}+$ oxaliplatin $10 \mathrm{mg} / \mathrm{kg} / \mathrm{week}$ by intraperitoneal injection, 8 mice 
received vehicle once a week by intraperitoneal injection. The injection was cancelled if weight loss was superior to $20 \%$ of the initial weight.

Tumor growth was assessed with a numeric caliper once a week for 4 weeks. Sacrifice occurred after a threshold of a maximum tumor size in order to comply with ethical guidelines. Tumor volume was calculated as follows: TV $(\mathrm{mm} 3)=(\mathrm{L} \times \mathrm{W} 2) / 2$, where $\mathrm{L}$ is the longest and $\mathrm{W}$ the shortest radius of the tumor in millimeters. Results were expressed as means \pm standard deviation of tumor volumes. Data were analyzed with Cox and Anova model.

\section{Clinical score}

A clinical score based on 4 items: diarrhea (scoring $0=$ absence to $1=$ presence), fatigue $(0=$ normal activity, $1=$ diminution of locomotor activity, $2=$ prostration $)$, alopecia $(0=$ none, $1=$ mild, $2=$ severe $)$, weight loss $(0=$ none, $1=10-20 \%, 2=>20 \%)$ was calculated by 2 different investigators, twice a week.

\section{Oxaliplatin induced peripheral neuropathy assessment}

Chronic oxaliplatin induced peripheral neuropathy was assessed with a Von Frey Test (39)(40)(29). Von Frey test assesses chronic hypoesthesia induced by oxaliplatin peripheral neuropathy. Mice were accustomed to the test twice a week during 2 weeks before tumoral injection. The Von Frey test is standardized, with the same experimental conditions to limit stress on animals. Mice are placed on a grid, after 5 minutes when the mouse is calm and motionless, a hind paw is touched with the tip of a flexible fiber of given length and diameter. The fiber is pressed on the plantar surface with a vertical force. Once the fiber bends the force applicated is maximal. Thus, a reproductible force can be applied by the investigator. It is known that rodents withdraw their paw as soon as it is touched (41). The Von Frey standardized kit includes filaments with bending force from $0.008 \mathrm{~g}$ to $300 \mathrm{~g}$. Each filament was tested from the lower force until the mouse pulled back its paw, considering the Von Frey test positive. Paw 
movements associated with locomotion were not counted as a withdrawal response. The control group (receiving vehicle) was considered as a reference for normal Von Frey values.

\section{Samples analysis}

After sacrifice, mice blood was analyzed to assess blood cell count, renal function (urea) and alanine aminotransferase. Advanced oxidation protein products on blood sample were measured with a spectrofluorometer (Fusion ${ }^{\circledR}$, Packard).

Polymerase chain reaction (PCR) for VEGF (Vascular Endothelial Growth Factor) was processed with tumoral samples of each group. Total mRNA was extracted from crushed tumoral samples with Trizol reagent (Invitrogen). The qRT-PCR was performed with a Quanti Tect SYBR ${ }^{\circ}$ Green RT-PCR kit on a Light Cycler 480 II instrument (Roche Applier Science, France). We used RTQ RT-PCR for the relative quantification of VEGF mRNA in tumor specimens, using $\beta$-actin mRNA as an internal control. The relative fold-change was calculated to the reference group using the formula $-2^{\Delta \Delta \mathrm{Ct}}$.

Autophagy assessment with measurement of LC3 and SQSTM1 production was performed through western blots on tumoral samples of each group. Tumor cells were lysed in ice-cold RIPA buffer, supplemented with $25 \mathrm{mmol} / \mathrm{L}$ sodium fluoride, anti-protease $1 \%$ ans 0.5 $\mathrm{mmol} / \mathrm{L}$ sodium orthovanadate. Equal amounts of proteins were loaded and separated by $10 \%$ sodium dodecyl-sulfate-polyacrylamide gel electrophoresis (45101023Biorad®, France). After transfer and blocking with 5\% fat free milk and 0.1\%tween in PBS, nitrocellulose membrane was incubated overnight at $4^{\circ} \mathrm{c}$ with a 1:1000 dilution of an anti-mouse SQSTM1 monoclonal antibody (20839, Invitrogen, Thermofisher ${ }^{\circledR}$, USA) and a 1:1000 dilution of a anti LC3 monoclonal antibody (3868, Cellsignal ${ }^{\circledR}$, MA, USA). Specific unconjugated proteins were detected using a 1:10000 dilution of a horseradish pedoxidase conjugated goat 
anti-Rabbit IgG (A16104, Thermofisher ${ }^{\circledR}$, USA) and visualized by an enhanced chemiluminescence system (Advansta Diagomics, France).

A part of each tumour was treated with formalin for histological analysis, after paraffin inclusion, transversal sections of $5 \mu \mathrm{m}$ were made. Vital coloration with hematoxylin and eosin were applied on tumoral tissue. Immuno-staining for Caspase 3 antibody (32351Abcam ${ }^{\circledR}$, Cambridge, USA), revealed with an anti-Rabbit antibody was realized on 3 tumoral sections of each group. Paw skin was also included in paraffin after formalin treatment, and an histological analysis with Luxol Fast Blue protocol was made (42)(43).

\section{Statistics}

Statistical analysis was performed using GraphPad Prism 5 and Excel v.16.48. Student $t$ test and ANOVA and Dunnett test were performed. The $\mathrm{p}$ valued were denoted as follows: ${ }^{*} \mathrm{p}<0.05$, $*^{*} \mathrm{p}<0.01, * * * \mathrm{p}<0.001, * * * * \mathrm{p}<0.0001$. Artwork was created with GraphPad Prism 5 and Excel v.16.48. 


\section{- Ethical Approval and Consent to participate:}

All animal manipulations were presented and approved by the Ethics Comitee of Paris University (Saisine \#8394). Consent to participate: not applicable.

- Consent for publication: Not applicable

\section{- Availability of supporting data;}

The datasets during and/or analysed during the current study available from the corresponding author on reasonable request.

\section{- Competing interests:}

The authors declare that they have no competing interests.

\section{- Funding: None}

\section{- Authors' contributions:}

A: conceived and designed the experiment and the analysis, B: performed experiments and collected the data, C: contributed to collection of data or analysis tools, D: performed the analysis, E; wrote the paper, F: Revised the manuscript.

Caroline Prieux-Klotz : A, B, C, D, E,

Hélène Bertrand : A, C, D, F

Sandrine Chouzenoux : B, C, F

Charlotte Chène : $\mathrm{B}, \mathrm{C}, \mathrm{F}$

Marine Thomas : B, C

Clotilde Policar: A, C, D, F

Frédéric Batteux : A, F

Carole Nicco: A, B, C, F

Romain Coriat, A, C, D, F

\section{- Acknowledgements:}

We thank Dr Thierry Tchenio for his expertise in cell cultures and in vitro experimentations.

\section{- Authors' information:}

$\mathrm{CPK}$ and $\mathrm{RC}$ are digestive oncologists, $\mathrm{HB}$ and $\mathrm{CP}$ are doctors in chemistry, $\mathrm{SC}$ and MT are laboratory technicians, $\mathrm{CC}$ is a $\mathrm{PhD}$ student and FB and $\mathrm{CN}$ are $\mathrm{PhD}$ and HDR holders. 


\section{REFERENCES}

1. Lebovitz RM, Zhang H, Vogel H, Cartwright J, Dionne L, Lu N, et al.

Neurodegeneration, myocardial injury, and perinatal death in mitochondrial superoxide dismutase-deficient mice. Proc Natl Acad Sci U S A. 3 sept 1996;93(18):9782-7.

2. Nicco C, Batteux F. ROS Modulator Molecules with Therapeutic Potential in Cancers Treatments. Molecules. 31 déc 2017;23(1).

3. Laurent A, Nicco C, Chéreau C, Goulvestre C, Alexandre J, Alves A, et al. Controlling tumor growth by modulating endogenous production of reactive oxygen species. Cancer Res. 1 févr 2005;65(3):948-56.

4. Laurent A, Nicco C, Tran Van Nhieu J, Borderie D, Chéreau C, Conti F, et al. Pivotal role of superoxide anion and beneficial effect of antioxidant molecules in murine steatohepatitis. Hepatology. mai 2004;39(5):1277-85.

5. Malassagne B, Ferret PJ, Hammoud R, Tulliez M, Bedda S, Trébéden H, et al. The superoxide dismutase mimetic MnTBAP prevents Fas-induced acute liver failure in the mouse. Gastroenterology. déc 2001;121(6):1451-9.

6. Alexandre J, Nicco C, Chéreau C, Laurent A, Weill B, Goldwasser F, et al. Improvement of the therapeutic index of anticancer drugs by the superoxide dismutase mimic mangafodipir. J Natl Cancer Inst. 15 févr 2006;98(4):236-44.

7. Ferret PJ, Hammoud R, Tulliez M, Tran A, Trébéden H, Jaffray P, et al.

Detoxification of reactive oxygen species by a nonpeptidyl mimic of superoxide dismutase cures acetaminophen-induced acute liver failure in the mouse. Hepatology. mai 2001;33(5):1173-80.

8. Burdon RH, Alliangana D, Gill V. Hydrogen Peroxide and the Proliferation of Bhk-21 Cells. Free Radical Research. janv 1995;23(5):471-86.

9. Salvemini D, Muscoli C, Riley DP, Cuzzocrea S. Superoxide dismutase mimetics. Pulm Pharmacol Ther. 2002;15(5):439-47.

10. Azzolin VF, Cadoná FC, Machado AK, Berto MD, Barbisan F, Dornelles EB, et al. Superoxide-hydrogen peroxide imbalance interferes with colorectal cancer cells viability, proliferation and oxaliplatin response. Toxicol In Vitro. avr 2016;32:8-15.

11. Doering M, Ba LA, Lilienthal N, Nicco C, Scherer C, Abbas M, et al. Synthesis and selective anticancer activity of organochalcogen based redox catalysts. J Med Chem. 14 oct 2010;53(19):6954-63.

12. Vilema-Enríquez G, Arroyo A, Grijalva M, Amador-Zafra RI, Camacho J. Molecular and Cellular Effects of Hydrogen Peroxide on Human Lung Cancer Cells: Potential Therapeutic Implications. Oxid Med Cell Longev. 2016;2016:1908164.

13. Coriat R, Marut W, Leconte M, Ba LB, Vienne A, Chéreau C, et al. The organotelluride catalyst LAB027 prevents colon cancer growth in the mice. Cell Death Dis. 11 août 2011;2:e191.

14. Adjuvant chemotherapy with oxaliplatin, in combination with fluorouracil plus leucovorin prolongs disease-free survival, but causes more adverse events in people with stage II or III colon cancer Abstracted from: Andre T, Boni C, Mounedji-Boudiaf L, et al. Multicenter international study of oxaliplatin/5-fluorouracil/leucovorin in the adjuvant treatment of colon cancer (MOSAIC) investigators. Oxaliplatin, fluorouracil, and leucovorin as adjuvant treatment for colon cancer. N Engl J Med 2004;350:2343-51. Cancer Treat Rev. déc 2004;30(8):711-3.

15. André T, Boni C, Mounedji-Boudiaf L, Navarro M, Tabernero J, Hickish T, et al. 
Oxaliplatin, fluorouracil, and leucovorin as adjuvant treatment for colon cancer. N Engl J Med. 3 juin 2004;350(23):2343-51.

16. Cunningham D, Starling N, Rao S, Iveson T, Nicolson M, Coxon F, et al. Capecitabine and oxaliplatin for advanced esophagogastric cancer. N Engl J Med. 3 janv 2008;358(1):36-46.

17. de Gramont A, Tournigand C, Louvet C, André T, Molitor JL, Raymond E, et al. [Oxaliplatin, folinic acid and 5-fluorouracil (folfox) in pretreated patients with metastatic advanced cancer. The GERCOD]. Rev Med Interne. 1997;18(10):769-75.

18. Vaccaro V, Sperduti I, Milella M. FOLFIRINOX versus gemcitabine for metastatic pancreatic cancer. N Engl J Med. 25 2011;365(8):768-9; author reply 769.

19. Lamarca A, Palmer DH, Wasan HS, Ross PJ, Ma YT, Arora A, et al. Second-line FOLFOX chemotherapy versus active symptom control for advanced biliary tract cancer (ABC-06): a phase 3, open-label, randomised, controlled trial. Lancet Oncol. 30 mars 2021; 20. Yang Y, Zhao B, Gao X, Sun J, Ye J, Li J, et al. Targeting strategies for oxaliplatininduced peripheral neuropathy: clinical syndrome, molecular basis, and drug development. J Exp Clin Cancer Res. 22 oct 2021;40(1):331.

21. Areti A, Yerra VG, Naidu V, Kumar A. Oxidative stress and nerve damage: role in chemotherapy induced peripheral neuropathy. Redox Biol. 2014;2:289-95.

22. Coriat R, Alexandre J, Nicco C, Quinquis L, Benoit E, Chéreau C, et al. Treatment of oxaliplatin-induced peripheral neuropathy by intravenous mangafodipir. J Clin Invest. janv 2014;124(1):262-72.

23. Glimelius B, Manojlovic N, Pfeiffer P, Mosidze B, Kurteva G, Karlberg M, et al. Persistent prevention of oxaliplatin-induced peripheral neuropathy using calmangafodipir (PledOx®): a placebo-controlled randomised phase II study (PLIANT). Acta Oncol. mars 2018;57(3):393-402.

24. Iranzo O. Manganese complexes displaying superoxide dismutase activity: a balance between different factors. Bioorg Chem. avr 2011;39(2):73-87.

25. Mathieu E, Bernard A-S, Delsuc N, Quévrain E, Gazzah G, Lai B, et al. A CellPenetrant Manganese Superoxide Dismutase (MnSOD) Mimic Is Able To Complement MnSOD and Exerts an Antiinflammatory Effect on Cellular and Animal Models of Inflammatory Bowel Diseases. Inorg Chem. 6 mars 2017;56(5):2545-55.

26. Miriyala S, Spasojevic I, Tovmasyan A, Salvemini D, Vujaskovic Z, St. Clair D, et al. Manganese superoxide dismutase, MnSOD and its mimics. Biochimica et Biophysica Acta (BBA) - Molecular Basis of Disease. mai 2012;1822(5):794-814.

27. Mathieu E, Bernard A-S, Delsuc N, Quévrain E, Gazzah G, Lai B, et al. A CellPenetrant Manganese Superoxide Dismutase (MnSOD) Mimic Is Able To Complement MnSOD and Exerts an Antiinflammatory Effect on Cellular and Animal Models of Inflammatory Bowel Diseases. Inorg Chem. 6 mars 2017;56(5):2545-55.

28. Cisnetti F, Lefèvre A-S, Guillot R, Lambert F, Blain G, Anxolabéhère-Mallart E, et al. A New Pentadentate Ligand Forms Both a Di- and a Mononuclear MnII Complex:

Electrochemical, Spectroscopic and Superoxide Dismutase Activity Studies. Eur J Inorg Chem. oct 2007;2007(28):4472-80.

29. Guillaumot M-A, Cerles O, Bertrand HC, Benoit E, Nicco C, Chouzenoux S, et al. Oxaliplatin-induced neuropathy: the preventive effect of a new super-oxide dismutase modulator. Oncotarget. 5 nov 2019;10(60):6418-31.

30. H. Chedotal PRS, M. Zoumpoulaki CP, H.C.Bertrand. Oxaliplatin - MnSOD mimics $\mathrm{Pt}(\mathrm{IV})$ conjugates, towards anticancer agents with reduced neurotoxicity- Under preparation. 31. Gibson D. Platinum(iv) anticancer prodrugs - hypotheses and facts. Dalton Trans. 16 août 2016;45(33):12983-91.

32. Kenny RG, Chuah SW, Crawford A, Marmion CJ. Platinum (IV) Prodrugs- A step 
closer to Ehrlich's vision? Eur J Inorg Chem. 2017;1596-612.

33. Nauseef WM. Detection of superoxide anion and hydrogen peroxide production by cellular NADPH oxidases. Biochim Biophys Acta. févr 2014;1840(2):757-67.

34. Bir SC, Shen X, Kavanagh TJ, Kevil CG, Pattillo CB. Control of angiogenesis dictated by picomolar superoxide levels. Free Radic Biol Med. oct 2013;63:135-42.

35. Karlsson J-E, El-Saadi W, Ali M, Puskar W, Skogvard P, Engvall JE, et al. Mangafodipir as a cardioprotective adjunct to reperfusion therapy: a feasibility study in patients with ST-segment elevation myocardial infarction. European Heart Journal Cardiovascular Pharmacotherapy. janv 2015;1(1):39-45.

36. Hanahan D, Weinberg RA. The hallmarks of cancer. Cell. 7 janv 2000;100(1):57-70. 37. Koustas E, Sarantis P, Theoharis S, Saetta AA, Chatziandreou I, Kyriakopoulou G, et al. Autophagy-related Proteins as a Prognostic Factor of Patients With Colorectal Cancer. Am J Clin Oncol. oct 2019;42(10):767-76.

38. Ciccarone F, Castelli S, Ciriolo MR. Oxidative Stress-Driven Autophagy acROSs Onset and Therapeutic Outcome in Hepatocellular Carcinoma. Oxid Med Cell Longev. 2019;2019:6050123.

39. Godinho PAR, Silva PGB, Lisboa MRP, Costa BA, Gifoni MAC, Rocha Filho DR, et al. Electronic von Frey as an objective assessment tool for oxaliplatin-induced peripheral neuropathy: A prospective longitudinal study. Eur J Cancer Care (Engl). janv 2021;30(1):e13360.

40. Micov AM, Tomić MA, Todorović MB, Vuković MJ, Pecikoza UB, Jasnic NI, et al. Vortioxetine reduces pain hypersensitivity and associated depression-like behavior in mice with oxaliplatin-induced neuropathy. Prog Neuropsychopharmacol Biol Psychiatry. 20 déc 2020;103:109975.

41. Miraucourt LS, Moisset X, Dallel R, Voisin DL. Glycine Inhibitory Dysfunction Induces a Selectively Dynamic, Morphine-Resistant, and Neurokinin 1 Receptor- Independent Mechanical Allodynia. Journal of Neuroscience. 25 févr 2009;29(8):2519-27.

42. Snodgress AB, Dorsey CH, Lacey LB. Luxol fast blue staining of degenerating myelinated fibers. Anat Rec. juin 1961;140(2):83-90.

43. Moszczynski AJ, Volkening K, Strong MJ. Neurofilament Immunohistochemistry Followed by Luxol Fast Blue, for Staining Axons and Myelin in the Same Paraffin Section of Spinal Cord. Appl Immunohistochem Mol Morphol. août 2020;28(7):562-5. 


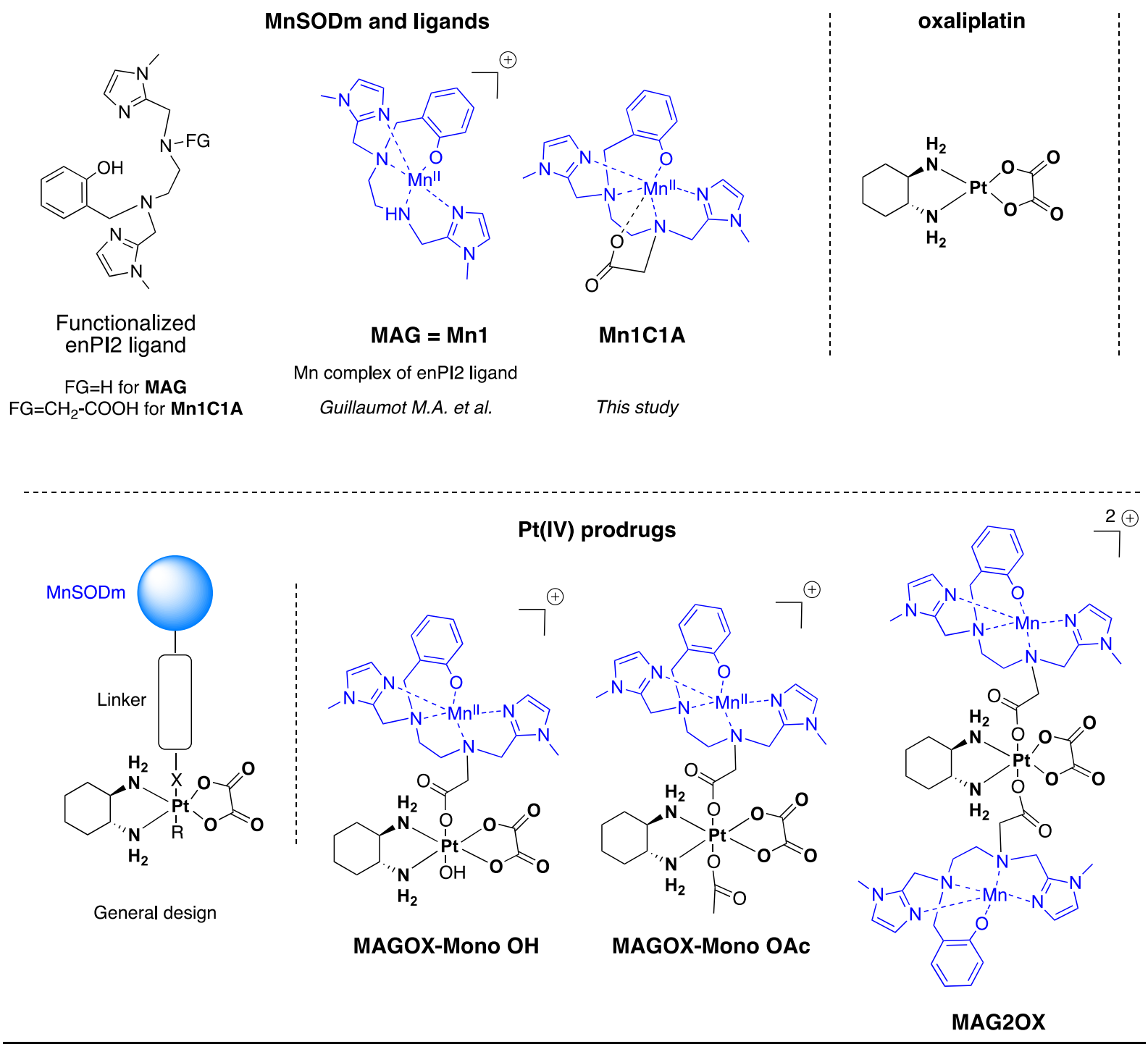

Figure 1: Chemical formula of the compounds studied MAGOX conjugates are Pt(IV) complexes combining oxaliplatin and Mn1C1A complex on axial position. 

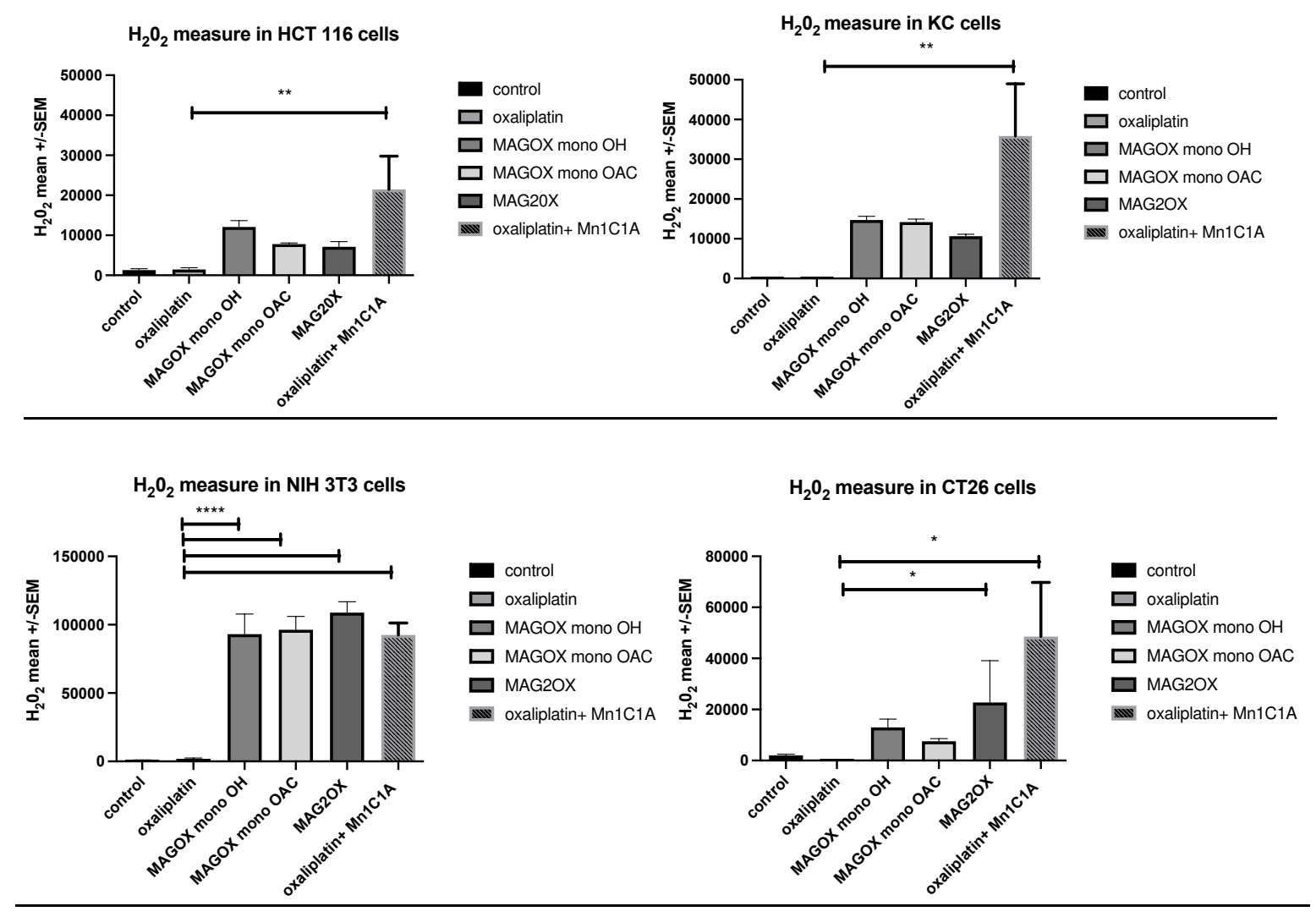

Figure $2: \mathrm{H}_{2} \underline{\mathrm{O}}_{2}$ production in vitro

$\mathrm{H}_{2} \mathrm{O}_{2}$ production was measured with spectrophotometry in cell lines treated with vehicle, oxaliplatin, MAGOX mono $\mathrm{OH}$, mono OAC, MAG2OX, Mn1C1A + oxaliplatin and oxaliplatin alone with the same concentration. $\mathrm{H}_{2} \mathrm{O}_{2}$ production reflected the $\mathrm{Mn} \mathrm{SOD}$ activity and was higher than oxaliplatin in all cell lines with conjugate compounds or with Mn1C1A + oxaliplatin $(p<0.05)$. 
Cristal violet viability HCT 116
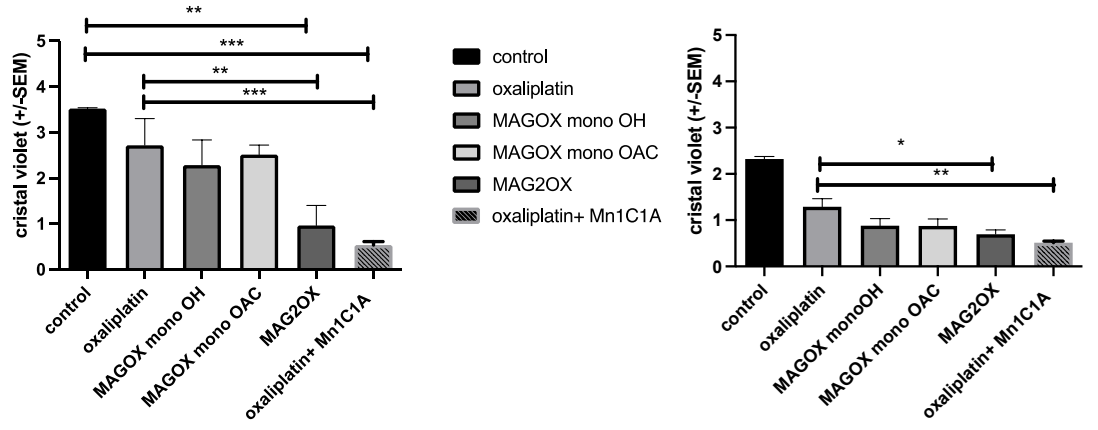

control

$\square$ oxaliplatin

$\square$ MAGOX monoOH

$\square$ MAGOX mono OAC

$\square$ MAG2OX

oxaliplatin+ Mn1C1A

Cristal violet viability NIH3T3
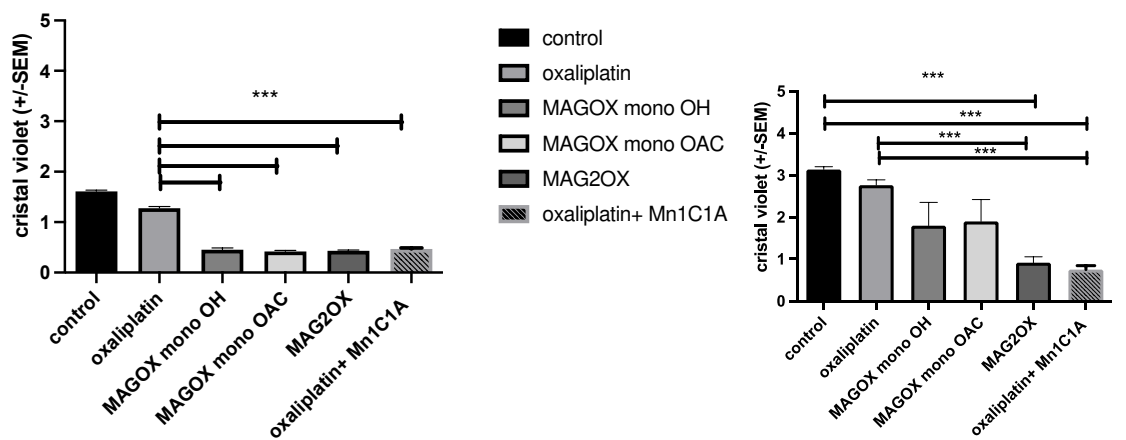

control

$\square$ oxaliplatin

MAGOX mono OH

$\square$ MAGOX mono OAC

$\square$ MAG2OX

oxaliplatin+ Mn1C1A

Figure 3 : Cristal Violet cell viability assessed at day $\mathbf{2}$ after 24 hours of treatment exposure Cristal violet cell viability was assessed at day 2 in all cell lines after 24 hours of treatment exposure to vehicle, oxaliplatin, MAGOX mono OH, MAGOX mono-OAC, MAG2OX, and Mn1C1A + oxaliplatin. Different concentrations were tested: 2.5, 5 and $10 \mu \mathrm{M}$. In all cell lines, cytotoxic activity was higher than oxaliplatin in cells treated with MAG2OX and with Mn1C1A +oxaliplatin $(p<0.05)$. 


\section{Cristal violet viability in primary fibroblast culture}

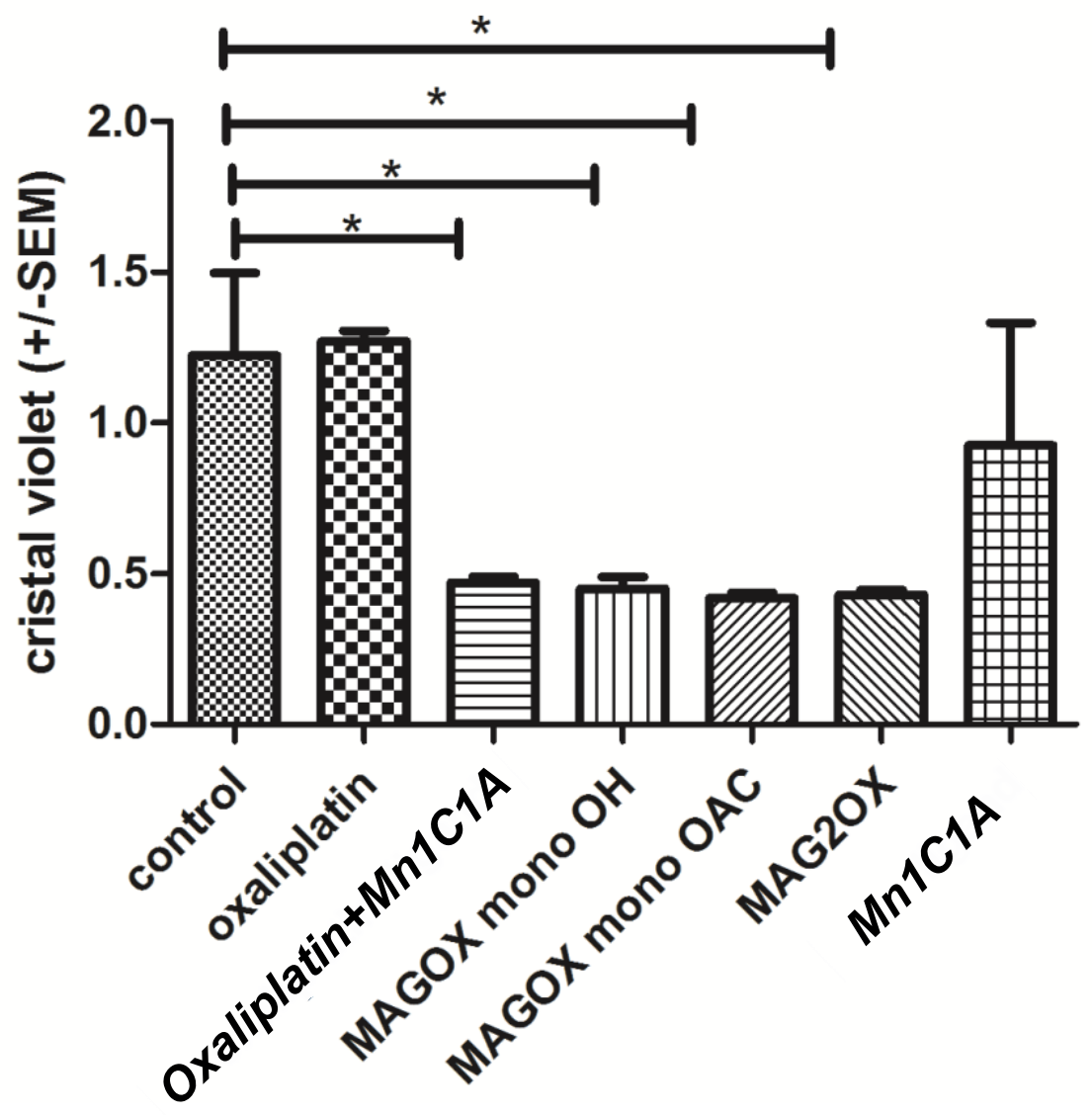

Figure 4: Cristal violet viability of fibroblasts treated with conjugates, oxaliplatin and vehicle.

Primary fibroblasts from murine skin cells were treated with vehicle, oxaliplatin, oxaliplatin associated with Mn1C1A, Mn1C1A alone, MAGOX mono OH, MAGOX mono OAc, and MAG2OX. Concentrations tested for each molecule were: 2,5, 5 and $10 \mu \mathrm{M}$. All the conjugate compounds and the association of oxaliplatin with Mn1C1A were more cytotoxic than oxaliplatin and vehicle on primary fibroblasts. The Mn1C1A showed no cytotoxic activity on murine primary fibroblast cells. 


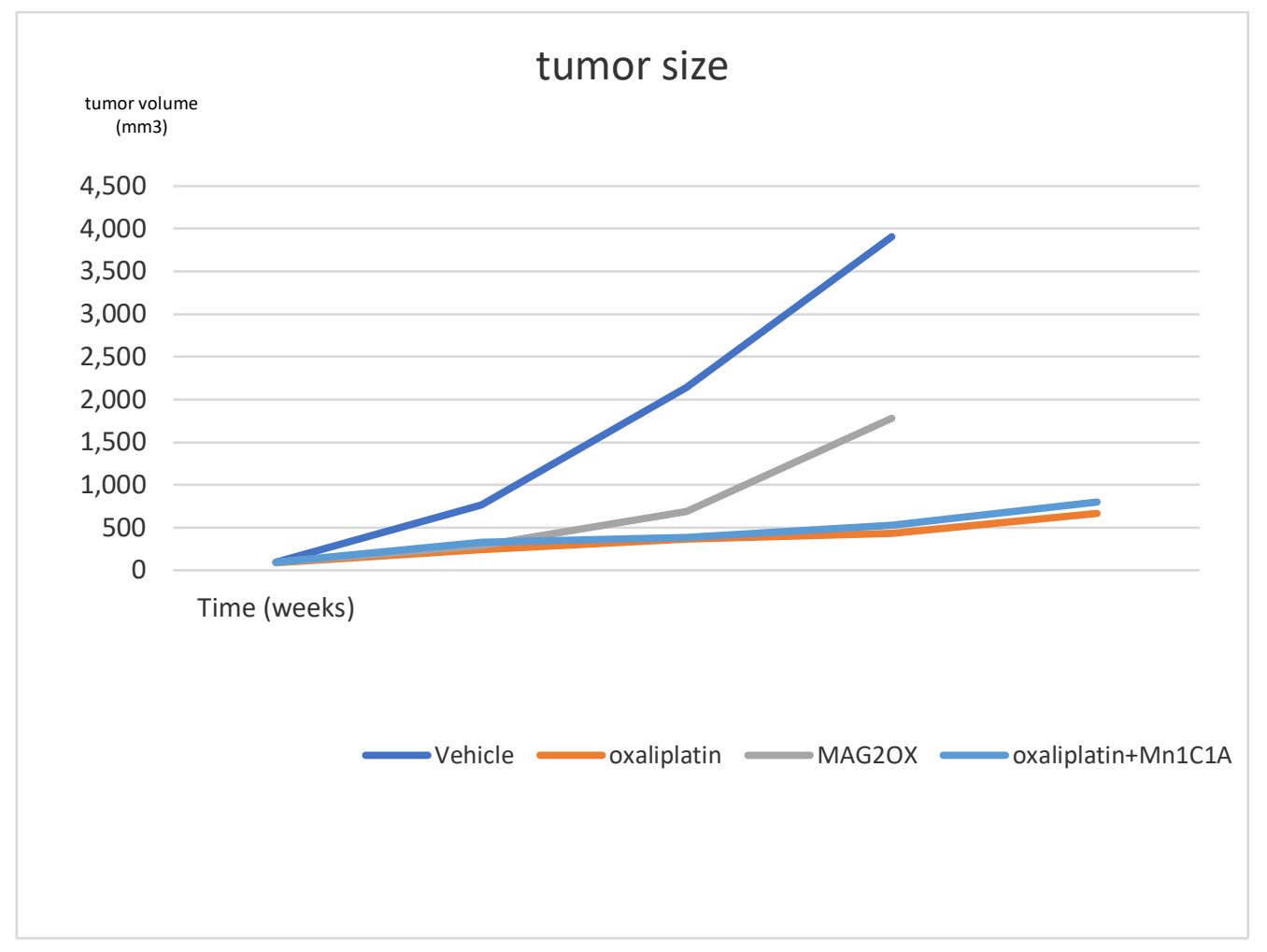

Figure 5: Tumor volume $\left(\mathrm{mm}^{3}\right)$ evolution with time in Balb/c mice treated with vehicle, oxaliplatin, MAG2OX and Mn1C1A+oxaliplatin.

$B A L B / c$ mice inoculated with CT26 cells creating a murine model of colorectal cancer were treated by vehicle, oxaliplatin, MAG2OX, Mn1C1A + oxaliplatin with weekly intraperitoneal injections. Tumor growth was exponential with vehicle. MAG2OX treatment had a higher antitumoral activity than vehicle but a lower antitumoral activity than oxaliplatin alone. The Mn1C1A associated with oxaliplatin had the same antitumoral activity than oxaliplatin alone. 
$\infty$

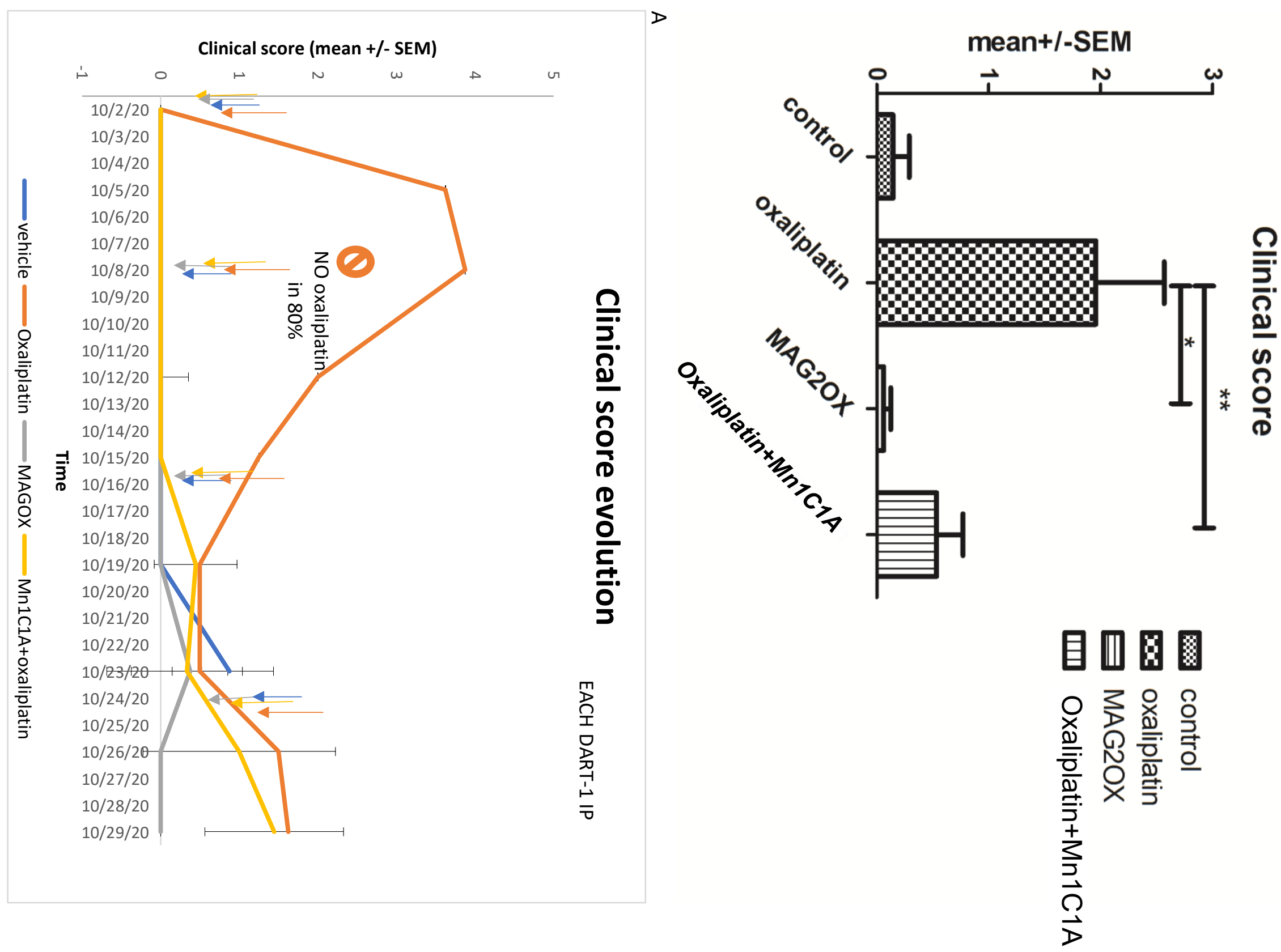


Figure 6: Clinical score in BALB/c mice inoculated with CT 26 tumoral cells treated with vehicle, oxaliplatin, Mn1C1A+ oxaliplatin and MAG2OX.

The clinical score was evaluated on each mouse, blindly by the investigator calculated with 4 criteria: asthenia, alopecia, diarrhea and weight loss. The score was proportional to treatment toxicity.

Fig 6 A shows the mean clinical score in each group depending on treatment received.

Oxaliplatin showed significant higher clinical toxicity than MAG2OX and Mn1C1A+ oxaliplatin with the same doses of oxaliplatin received ( $p<0.05)$.

Figure $6 \mathbf{B}$ shows the clinical score evolution over time. Each dart represents 1 intraperitoneal injection of each treatment. In the oxaliplatin group, $80 \%$ of the mice did not receive the second oxaliplatin IP injection due to a weight loss $>20 \%$. In the Mn1C1A + oxaliplatin and the MAG2OX group, clinical score raised with tumor growth over time but no significant toxicity was observed and every IP injection could be received. 


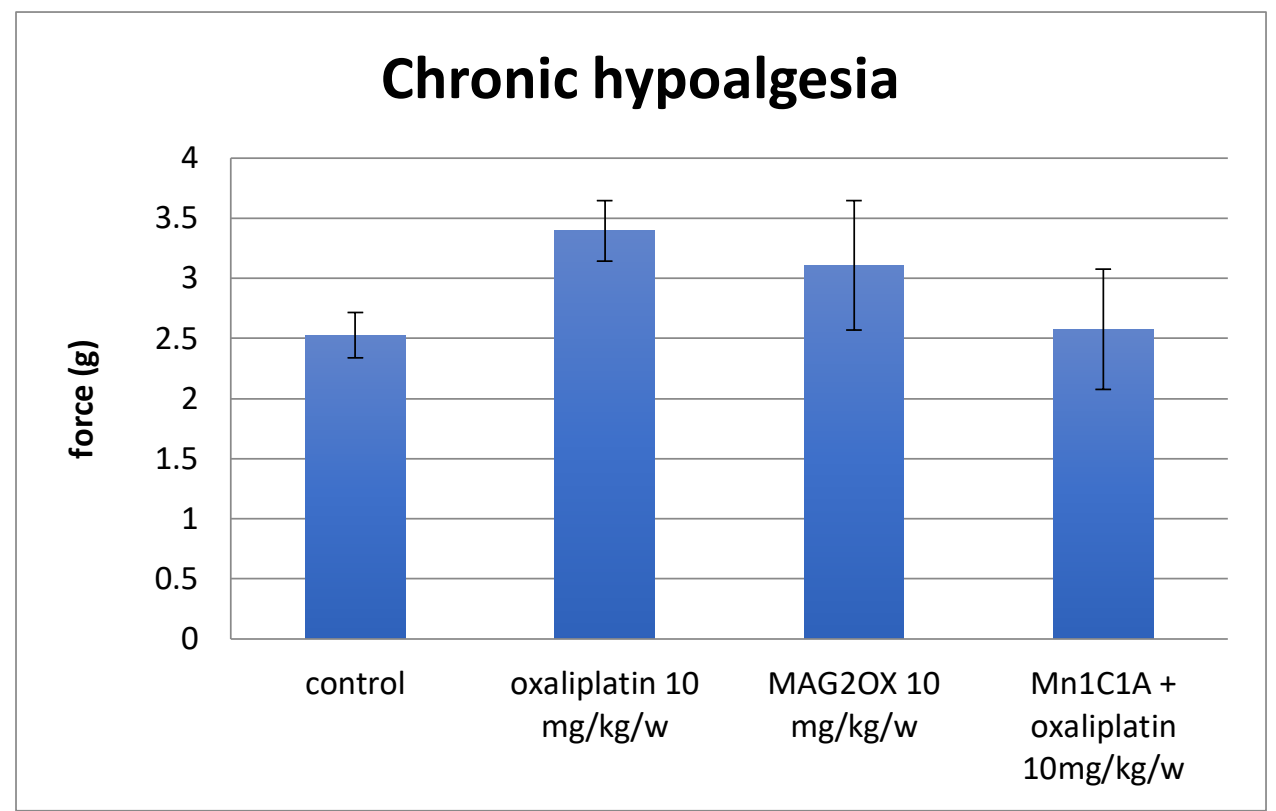

A

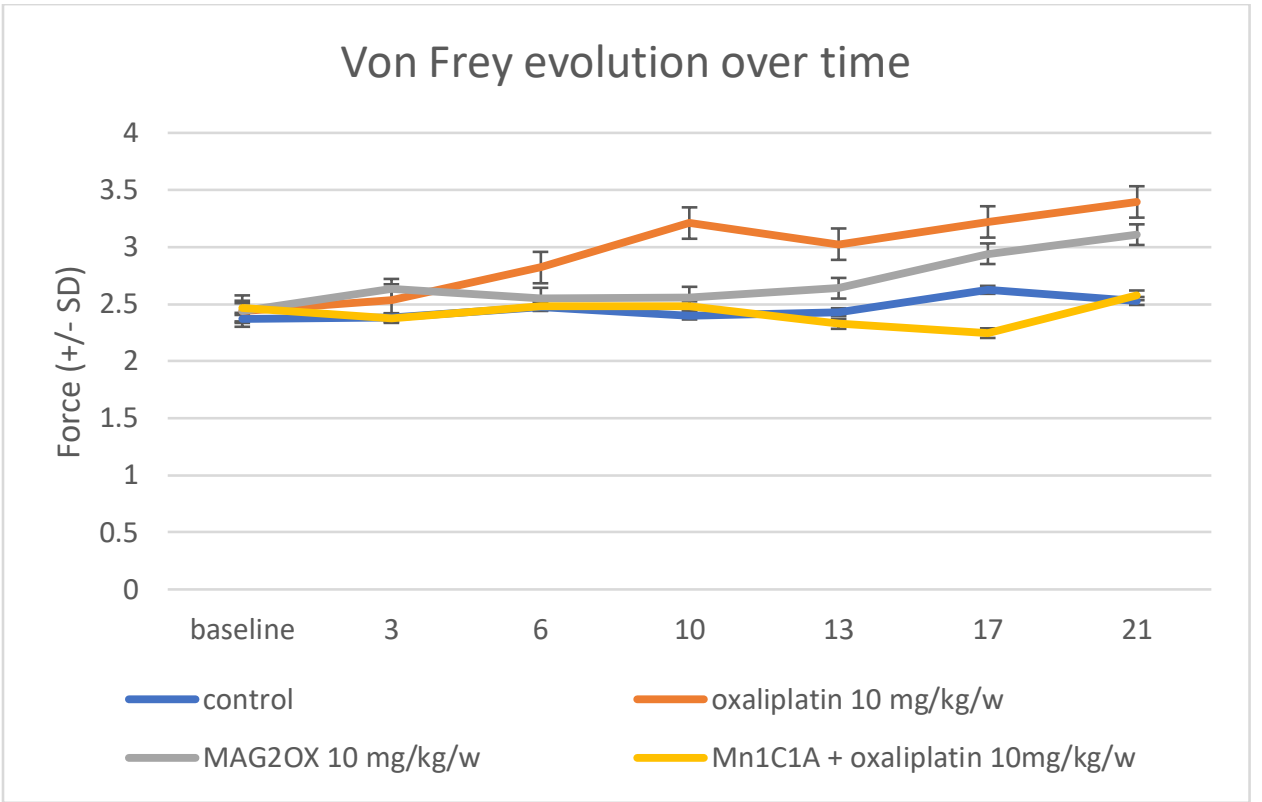

B

Figure 7: Von Frey test evaluating chronic hypoalgesia reflecting oxaliplatin induced neuropathy In mice treated with oxaliplatin, vehicle, MAG2OX or Mn1C1A+oxaliplatin.

Figure 7A reflects mean Von Frey during the whole experiment, showing a statistical significance between Mn1C1A+oxaliplatin with less hypoalgesia than oxaliplatin alone $(p<0.05)$.

Figure 7B reflects Von Frey score evolution over time (days) in the different groups.

$B A L B / c$ mice were acclimated with Von Frey before the tumoral cells (CT26) subcutaneous injection and before randomization and the Von Frey basal score was the same in each group. In the oxaliplatin group, hypoalgesia appeared after the first oxaliplatin injection and worsened over time. In the MAG2OX group, hypoalgesia appeared later and with less intensity but no statistical difference was showed compared to oxaliplatin. Thus, in the 
Mn1C1A associated with oxaliplatin, no hypoesthesia appeared at the end of the experiment. The difference was statistically significant and showed a neuroprotective activity of $\mathrm{Mn} 1 \mathrm{C} 1 \mathrm{~A}$ associated with oxaliplatin compared to oxaliplatin alone. 


\section{AOPP}

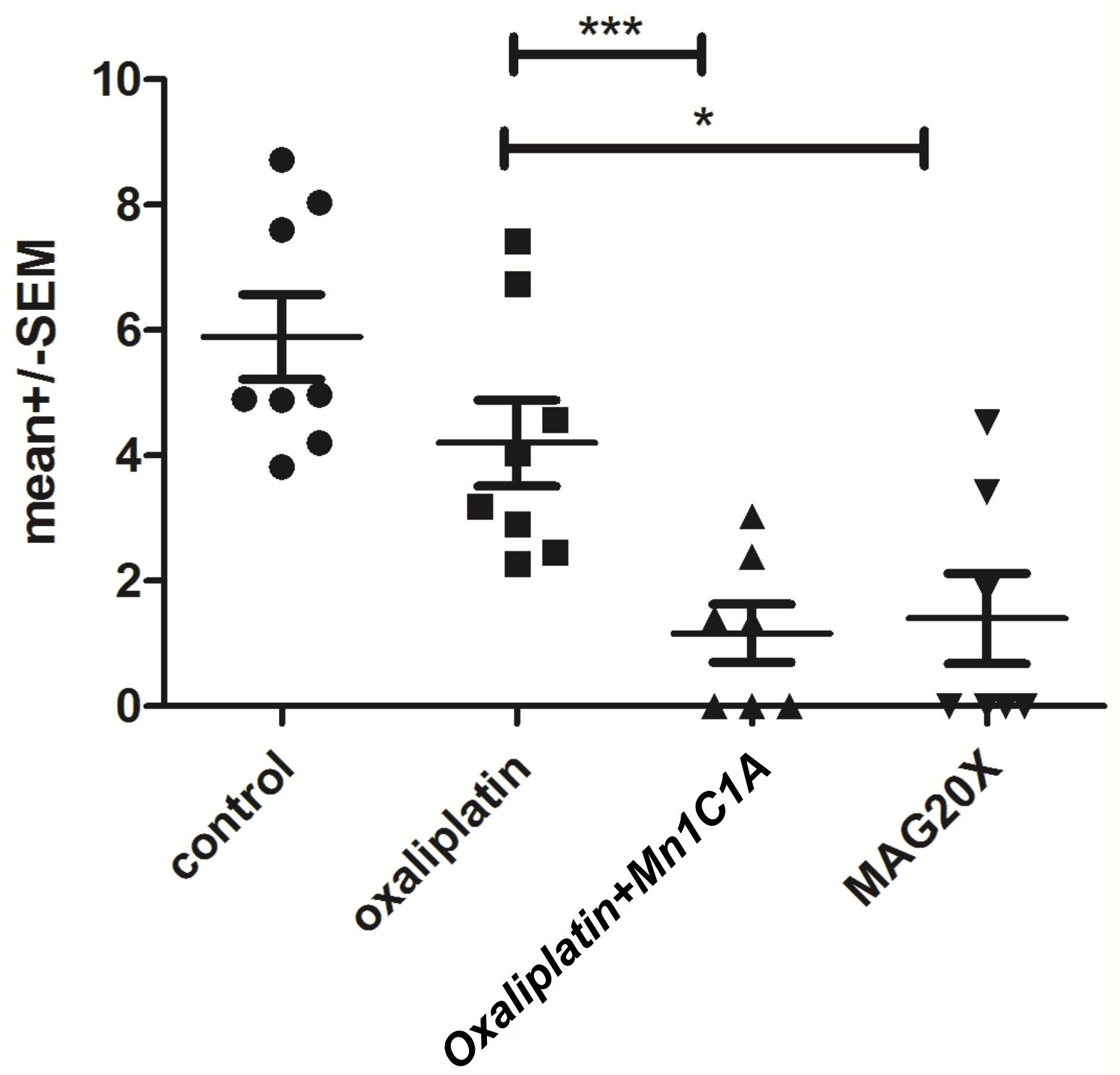

Figure 8 : Mean Advanced oxidation protein products (AOPP) measured in mice serum

After sacrifice of mice treated with intraperitoneal vehicle, oxaliplatin, Mn1C1A associated with oxaliplatin or MAG2OX, serum was analysed and the advanced oxidation protein products were measured. In the sera of mice treated with Mn1C1A+ oxaliplatin and with MAG2OX, AOPP levels were significantly lower than the vehicle and the oxaliplatin group $(p<0.05)$, reflecting a seric Mn SOD activity. 


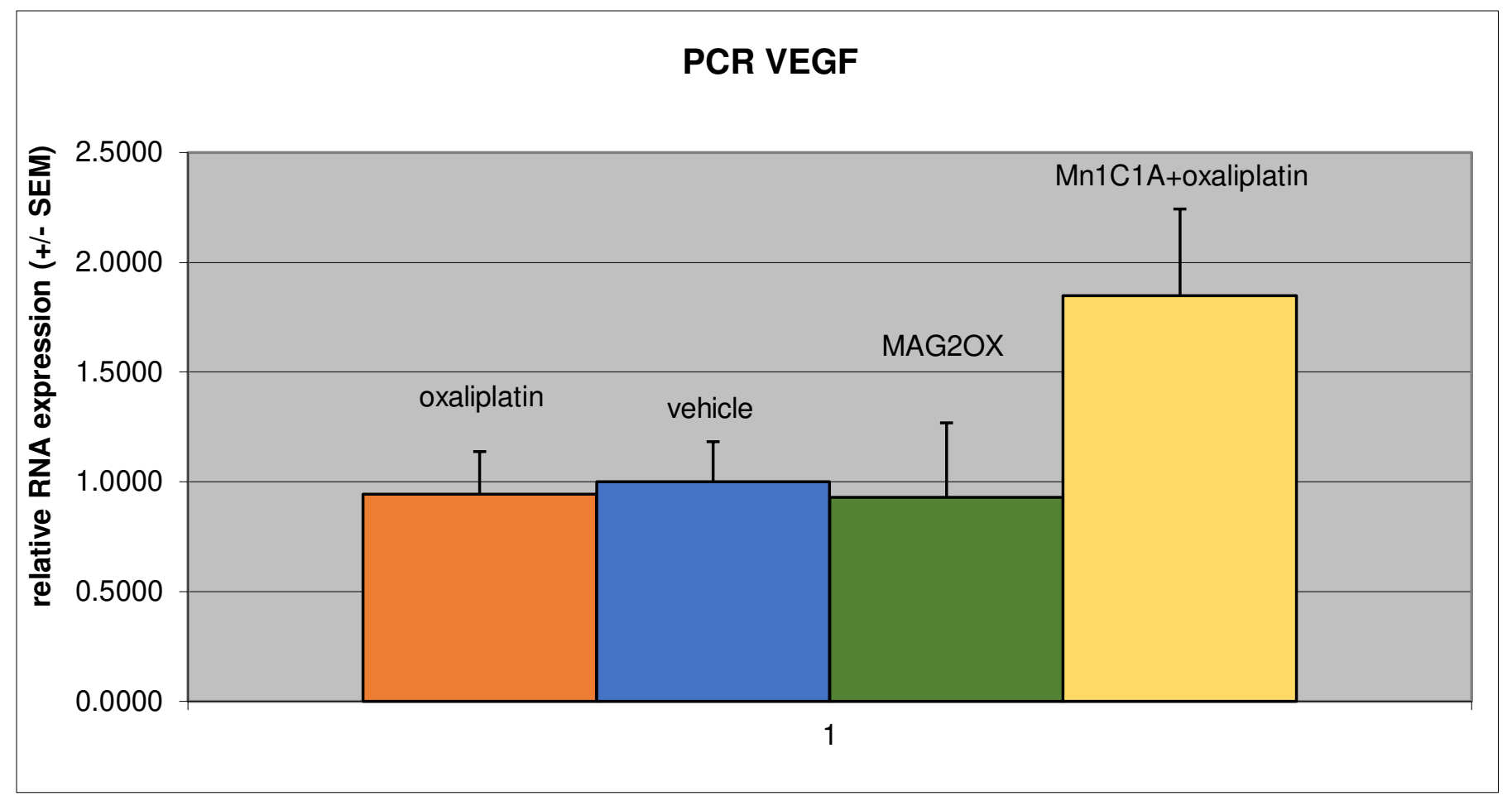

A

\section{LC3 tumoral production}

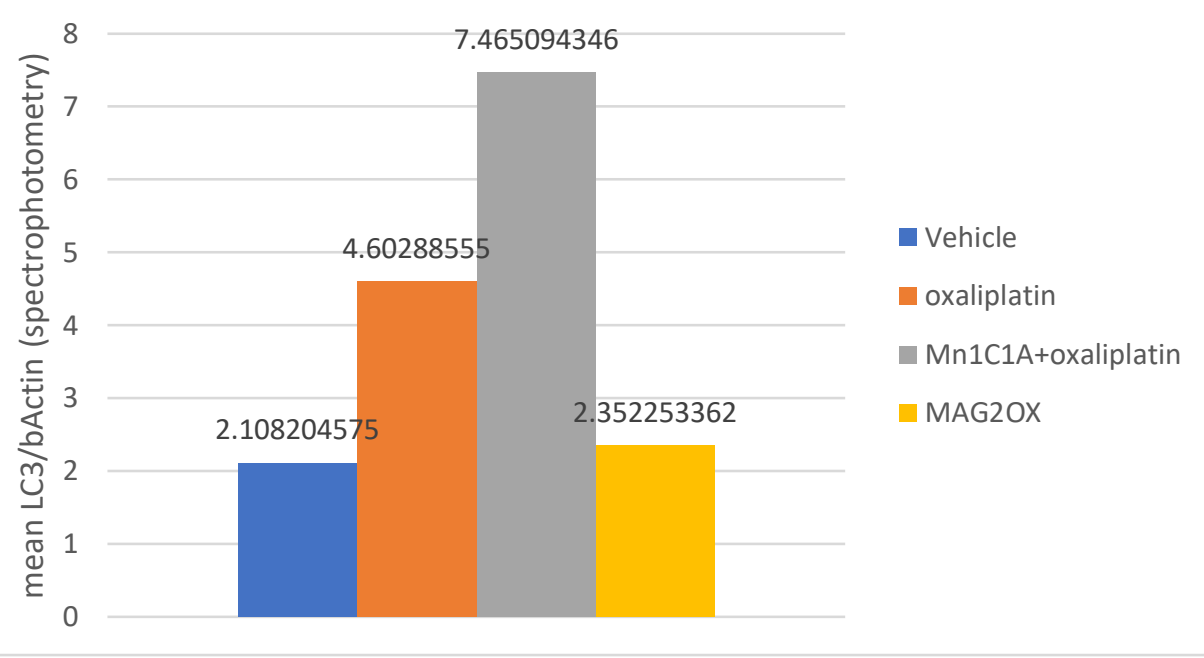

B

Figure 9: PCR VEGF and western blot for autophagy markers: LC3 and SQSTM1 expression in mice tumors.

Figure 9A: PCR VEGF expression in tumoral tissue of mice treated with oxaliplatin, vehicle, MAG2OX or Mn1C1A+ oxaliplatin

Figure 9B: Western blot for LC3 production in tumoral tissue of mice treated with oxaliplatin, vehicle, MAG2OX or Mn1C1A+ oxaliplatin

After sacrifice, tumoral RNA of mice treated with vehicle, oxaliplatin, Mn1C1A+oxaliplatin and MAG2OX were extracted. A PCR of VEGF expression was realized, showing a significant higher RNA VEGF production in tumors of mice treated with Mn1C1A + oxaliplatin compared to the other groups. 
Tumoral proteins were also extracted and a western blot measuring LC3 expression reflecting autophagy was performed. In the Mn1C1A+ oxaliplatin group, LC3 production was significantly higher compared to the other groups, reflecting more autophagy occurrence. 


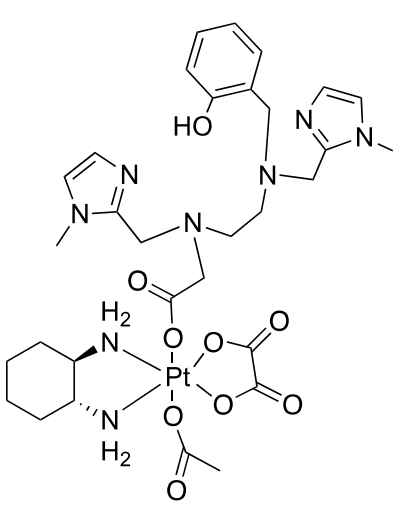

MAGOX

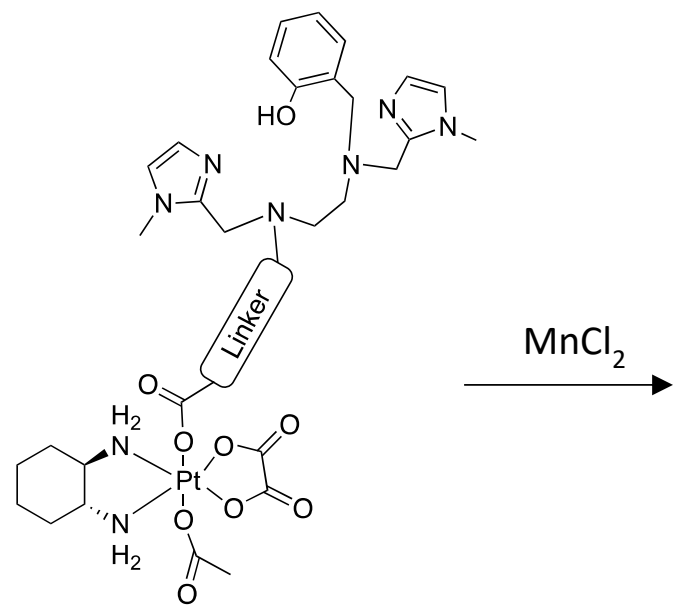

New MAGOX generation<smiles></smiles>

oxaliplatin (Ptll)

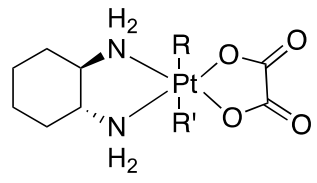

$\mathrm{Pt}(\mathrm{IV})$ species

Pt species

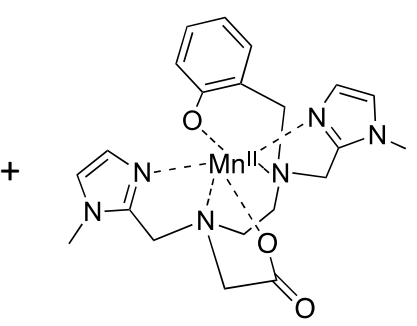

Mn1C1A

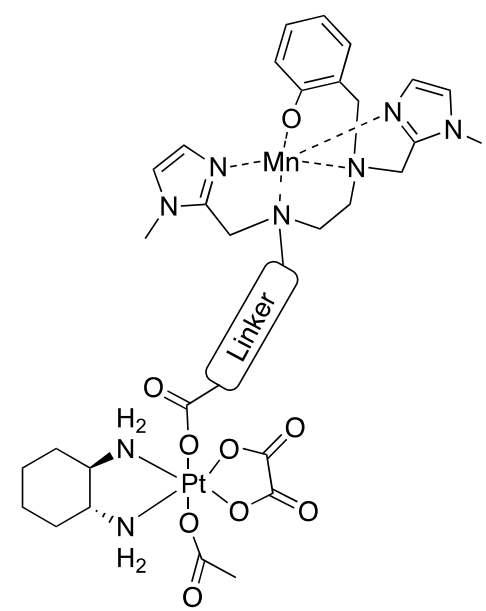

Figure 10. Degradation of first MAGOX series upon coordination of Mn during in situ preparation. 


\section{Supplementary Files}

This is a list of supplementary files associated with this preprint. Click to download.

- supplementaryS1S2.docx 